Supporting information

\title{
Electrocatalytic Applications of Nanosized Pt Particles Self-Assembled on Sol-Gel Derived Three-Dimensional Silicate Network
}

\author{
Bikash Kumar Jena and C. Retna Raj* \\ Department of Chemistry \\ Indian Institute of Technology \\ Kharagpur 721 302, India \\ E-mail: crraj@chem.iitkgp.ernet.in \\ Fax: +91-3222-282252; Tel: +91-3222-283348
}

Figure 1S

UV-Visible spectra for (a) $\mathrm{H}_{2} \mathrm{PtCl}_{6}$ solution and (b) colloidal nPts.

\section{Figure 2S}

TEM image obtained for colloidal nPts.

\section{Figure 3S}

FTIR spectra for MPTS modified gold plate $(a, b)$ before and (c) after self-assembling of nPts.

\section{Figure 4S}

EDS data obtained for the self-assembling of nPts on MPTS modified coverslip.

\section{Figure 5S}

Plot of area vs self-assembling time for nPts on silicate network. 


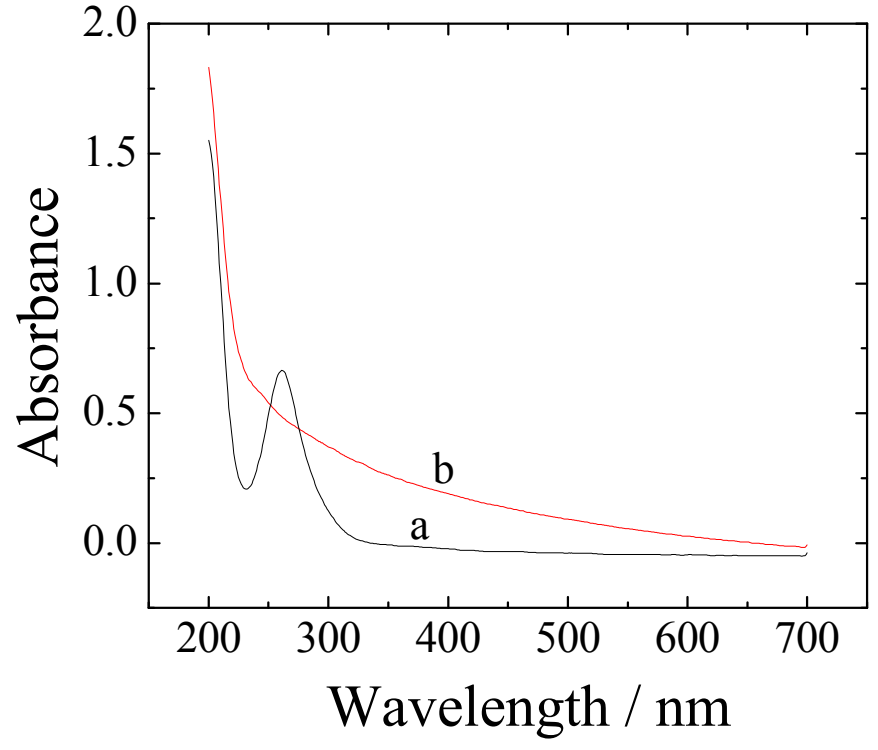

Figure 1S

Raj, C.R. 


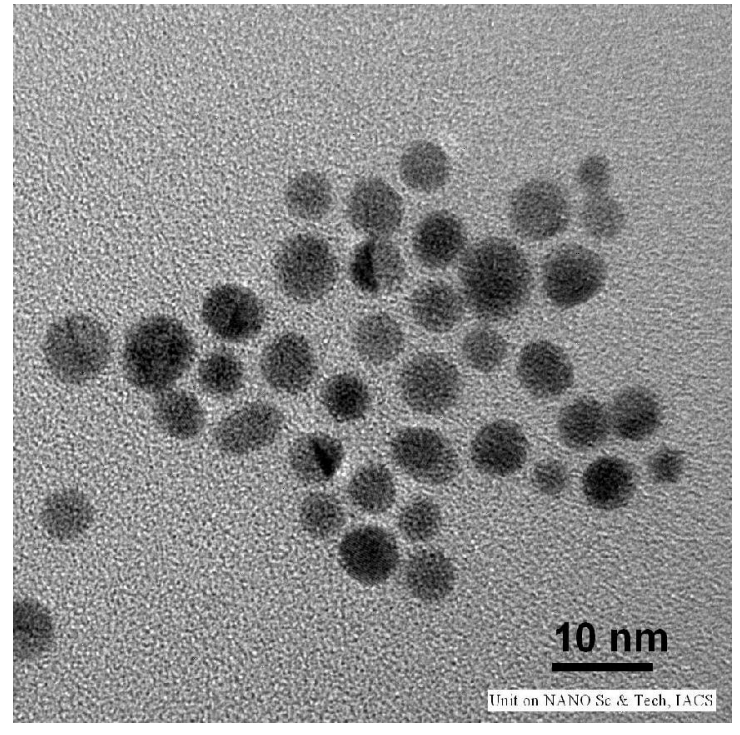

Figure 2S

Raj, C.R. 

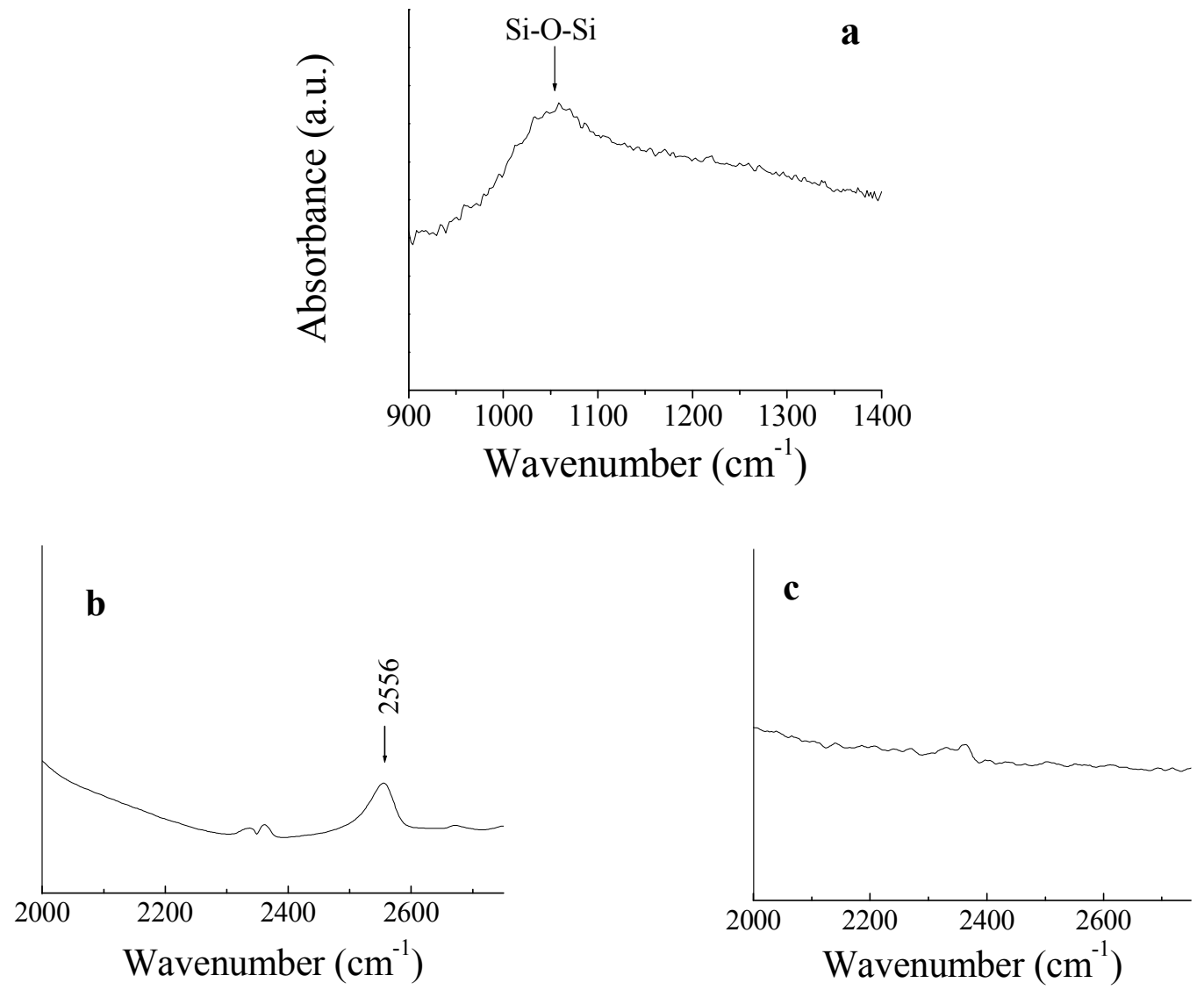

Figure 3S

Raj, C.R. 


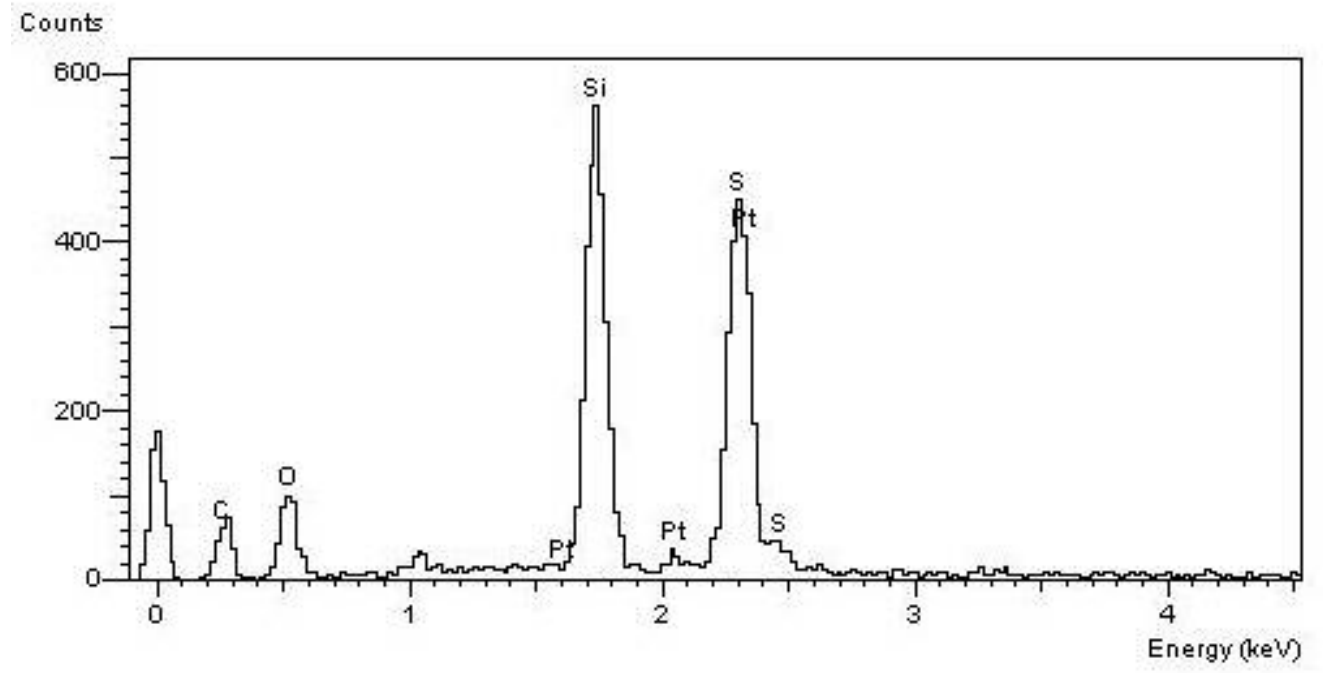

Figure 4S

Raj, C.R. 


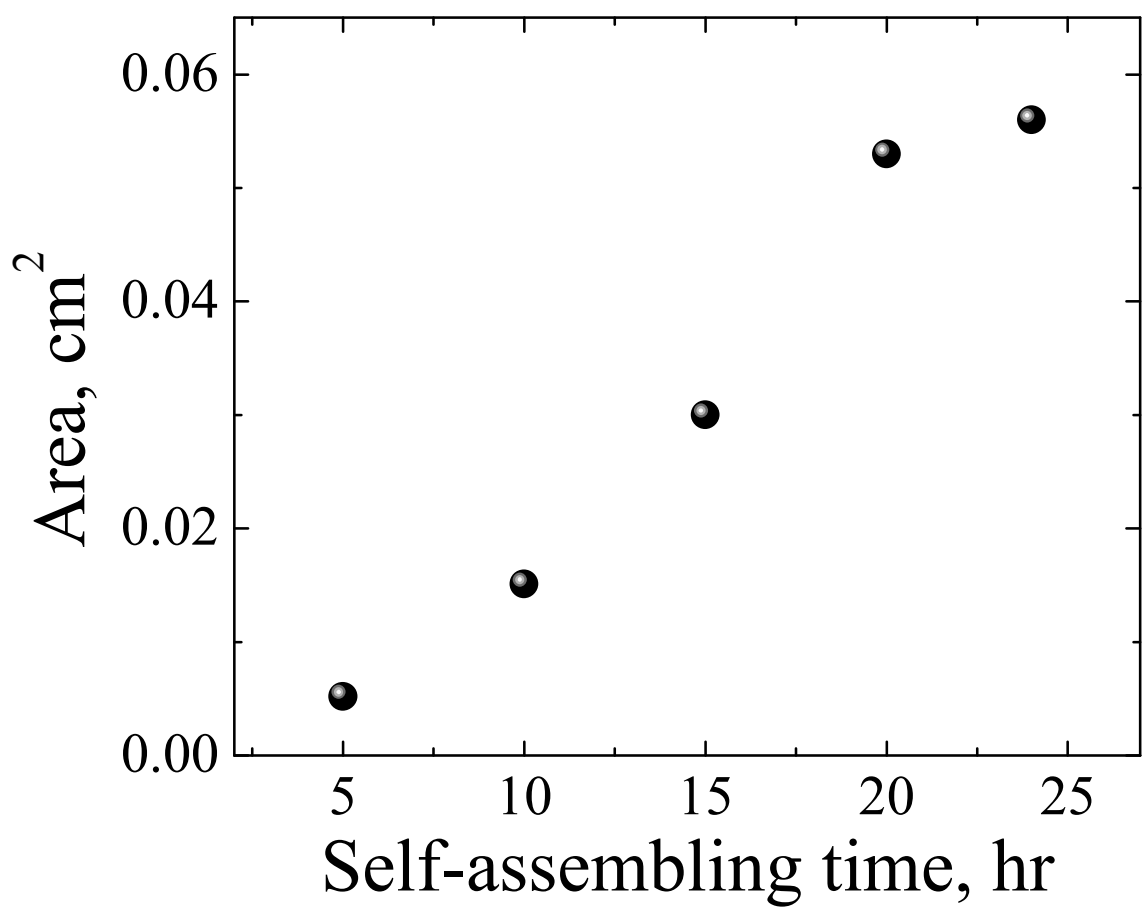

Figure 5S

Raj, C.R. 